\title{
Sociability through the Movement of Young Children: The Effects of Exercise Programs involving Rhythm Play on the Potential for Physical Expression
}

\author{
Eri Yoshimi ${ }^{1}$ \\ ${ }^{1}$ Tokiwakai College Early Childhood Education, Osaka, Japan \\ Correspondence: Tokiwakai College Early Childhood Education, Osaka, 547-0031, Japan.
}

Received: June 2, 2021

Accepted: June 27, 2021

Available online: June 28, 2021

doi:10.11114/ijsss.v9i4.5278

URL: https://doi.org/10.11114/ijsss.v9i4.5278

\begin{abstract}
This study aims to examine the potential for physical expression on the part of infants through observations of their motions before and after exercise programs, with an understanding of the potential for physical expression as the development of a sociality that seeks to communicate with other children in the experience of an exercise program. The 106 study participants comprised 29 three-year-olds, 44 four-year-olds, and 33 five-year-olds. During the exercise intervention period, a exercise program focusing on rhythm play was carried out for 6 minutes per day. The ability for physical expression was analyzed using 12 criteria related to the areas of motion, space, dynamics, time, and relationships, which revealed the characteristics of each grade of students. Significant interactions were observed in criteria 11 and 12, related to the area of relationships, across all grades. Specifically, in the efforts of those from around the age of four, which involved repeating motions in a particular rhythm, it was shown that this could be expected to greatly increase the impact on the potential for bodily expression. It was discovered that the experience of an exercise program involving rhythm play, even if they only experienced it a few times, brought a greater degree of richness to the movement of the children while at the same time expanding their awareness of other children and giving rise to behaviors through which they actively participated in communication.
\end{abstract}

Keywords: young children, potential for physical expression, social development, rhythm play

\section{Introduction}

\subsection{The Importance of Social Development in Early Childhood}

Physical expression, such as rhythm play, is considered an opportunity for children to express themselves by moving in tandem with a rhythm, expanding their consciousness away from themselves and towards others, supporting the development of both the mind and body, and promoting a rich variety of activity in young children.

At present, the lowering of basic exercise competencies is regarded as a problem in Japan, with guidelines for early childhood exercise being established. The "diversification of movements" described in the guidelines for early childhood exercise states that the number of types of movements will be increased and a variety of movements will be obtained through play that involves moving the body, as well as through general life experience. The "refinement of movements" is a process whereby the way one moves becomes more adept and immature movements are lessened through the accumulation of the experience of exercise from awkward movements. By accumulating experience of the "diversification of movements" and "refinement of movements" through play that involves moving their bodies, physical strength and the capacity to exercise will increase, and a smoothness of movement will be acquired. In addition, these experiences are thought to increase the motivation and interest of the young child surrounding participation in various activities, as well as nurturing their sociability through engagement with their surroundings.

The following studies have been conducted on the development of sociability through initiatives that have young children participate in exercise. Regular instruction in soccer classes that are cognizant of the characteristics of infant development and the acquisition of sociability has been suggested to have an effect on this sociability, such as through coordination among groups involved in soccer (Nakayama \& Nakai, 2012).

The first point in the aims and content section of the Nursery School Childcare Guidelines announced in 2017 for children 3 years of age or older states, "A) the development of motor function enables basic activities to be carried out 
while at the same time enabling independence around basic lifestyle habits. The number of words understood expands rapidly and intellectual as well as general interests increase. Through playing with peers, the perception of being one of these peers develops and collective play and cooperative activities come to be observed. Based on the characteristics of these developments, in nursery care during this period, it should be ensured that the growth of individuals and the fulfillment of activities as a group are promoted" (Ministry of Health, Labor and Welfare, 2017). In this way, it can be thought that a sense of self emerges from experiencing and feeling connections with peers via group play, and through group activities, exercise potential as well as society itself can be influenced. Sugimura et al. (2010) found that for children aged 4-6 years of age, through the motivation and positivity shown in such activities, such as proposing their ideas while at play, sociability and exercise are mutually enhanced. From these results, it has been clarified that moving the body raises awareness of interactions with others, and that group activities promote the development of individuals. Therefore, children's group activities in childcare settings manifest opportunities to promote the development of sociability; consequently, greater importance is attributed to the maintenance of the environment.

Regarding the impact and efficacy of rhythmic exercise and other forms of dance instruction on exercise performance, Evridiki, Aggeliki, and Vassiliki (2004), in a study examining children (aged 4-6 years) before they begin attending school, found that exercise potential was improved through the jumping and dynamic balancing of children who participate in programs in which the music and movements are suitable for their development, showing that rhythmic activities play a key role in exercise performance. Tomita, Otobuchi, and Matsushima (2014) demonstrated, through an independent rhythm exercise that aimed to increase aerobics, muscles, and flexibility, the effect of a certain rhythmic sensation by improving the physical fitness of young children who were asked to continuously jump over barriers. Takenawa, Takeda, Kikuchi, and Nakagawa (2008) observed, in a study of 3-5-year olds, that they enjoyed moving as part of aerobic instruction that incorporated coordination exercises. This suggests the possibilities of young children's movements; however; no concrete quantification of the results is offered. Thus, although it has been clarified that dance instruction such as rhythm exercise and aerobics can smoothen movement and enhance a sense of rhythm, few studies have clearly shown the influence of rhythm exercise instruction on the sociability of infants and their exercise ability.

\subsection{The Richness of Infant Movement and the Development of Sociability}

The following studies have been conducted concerning the development of infants and young children and the richness of their movements. Regarding the "meaning" of the physical expression of young children, Nasukawa and Ikeda (1995) considered the inner nature of the young child from their movements while they engage in jump rope. The inner nature of young children was observed through the desire for empathy and mental stability arising from engaging in jump rope, with further observation of the jump-rope motion becoming rhythmic and a change in communication behaviors, expressions, and feelings upon looking at the caregiver, with the young child trying to obtain a good timing and tempo. According to Furuichi (1996), regarding bodily expression in synchronous actions such as rhythmic dance, feelings of psychological and physical pleasure emerge through sharing the movement with other children. Moreover, the introduction of movement gives rise to further spontaneous movement, and mental development is promoted by sharing a rhythm. According to a study on the development of physical expressiveness in Wakamatsu $(1989,1990,1993)$ revealed that the movements of 3-year-old children are bigger; they have a greater diversification of expressions; and from their interactions with other children and caregivers, as they become expressive, it takes a long time for them to enjoy themselves. Four-year-old children have been observed to move rhythmically when combining two kinds of exercises using their torso, interacting with other children while using the space, and showing empathy as they moved. Five-year-old children showed spatial expansion through their movement through the space, as well as height differences, and it was observed that they enjoy expressing rhythmic movement that accurately grasps the timing using the whole-body in groups of five or six people. From this, it is understood that the physical expression of the young child increases with age, and the potential for physical expression increased in line with exercise capacity and social development. Moving rhythmically as a form of synchronized movement has been shown to expand opportunities for communication with other children, expand the spatial range of movements, and is linked to the enjoyment of movement. Kameyama (2008) showed that the practice of rhythmic dancing for 5-year-old and 6-year-old children contributes to the richness of expressive potential and expressive activity by (1) loosening the mind and body, (2) allowing them to enjoy dancing while feeling the rhythm, (3) developing activities centered on young children, (4) drawing images from movements, (5) allowing them to enjoy communication with others while cognizant of the expanse of the space, and (6) allowing them to experience expressive activities that bring out individual manners of expression.

From these results, it is considered that the richness of movement leads to the liberation of the mind and body through the practice of rhythmic movement, as well as nurturing a positive attitude in the young child who engages in the activity. That is, rhythmic exercise promotes active behavior in the young child, and interest in movement increases. The richness of movement frees the mind and body through the process of moving in tandem with the rhythm. In 
addition, a diversification of movements emerges from the extension of the scope of activities and opportunities for the individual to communicate with other children and groups, with the development of sociability seemingly brought about. These experiences have been shown to increase motivation to exercise, develop from experiences in which one moves in tandem with a rhythm to experience a variety of movements, and increase opportunities for voluntary movements, such as moving with someone or expressing one's movements to someone, while at the same time increasing the interest of young children in others. In other words, it is believed that the experience of rhythmic exercise in early childhood will liberate the mind and body through rhythmic movement, expand the scope of movement, and enrich movement by transitioning from individual to group involvement and by enjoying communication with other children, leading to the development of sociability.

\subsection{Research Purpose}

While previous studies have shown that the physical expression of young children expands the spatial range of opportunities for communication and movement with other children as part of synchronized exercise in which social development increases with age, there are no studies that have analyzed in detail the richness of movement of young children through rhythmic play and quantified them as potential for physical expression. The author has previously prepared and implemented a coordination exercise program centered on rhythm play, and has examined the richness of the movements of infants (Yoshimi, 2020a, 2020b; Yoshimi \& Katayama, 2019). In addition, Yoshimi, Nomura, and Kida (2021) attempted to quantify the potential for physical expression of children by adding relationship and social development criteria to the observational evaluation criteria on the richness of movement as part of an evaluation index. They confirmed the potential for physical expression through the development of a sociability that seeks to enable communication with other children through movement, and found that regardless of age, the development of exercise ability and sociability leads to a richness in the movements of young children. However, while the social development of young children through movement has been confirmed, there has been no detailed investigation made into the observation evaluation criteria such as the three criteria related to movements, two criteria related to space, two criteria related to dynamics, two criteria related to time, and three criteria related to relationships. In this study, by analyzing trends by age, we clarify how the development of sociability changes with the potential of physical expression ability and age of young children. The purpose of this study is to analyze the observation evaluation criteria in more detail and to clarify changes in the development of sociability due to communication through infant movements by age (hereafter, by grade).

\section{Method}

\subsection{Research Participants}

There were a total of 106 participants in this study, with 29 (mean age at initial measurement \pm 49.2 months: 10 boys and 19 girls) attending private kindergartens (hereinafter referred to as 3-year-old children), 44 (mean age at initial measurement \pm 62.84 months: 22 boys and 22 girls) attending middle-aged classes (hereinafter referred to as 4 -year-old children), and 33 (mean age at initial measurement \pm 73.48 months: 17 boys and 16 girls) attending elderly classes (hereinafter referred to as 5-year-old children). Twenty-one children in the 5-year-old group whose classes were closed on the experiment date and those who were absent on this date or refused to participate in the experiment were excluded from the sample (57.6\%). Study participants belong to middle class families.

\subsection{Procedures}

As an ethical consideration, the purpose of the study was explained to the head of research cooperation at the school, kindergarten teachers, and the guardians of the research participants in advance, with written consent obtained from guardians. This study was conducted with the approval of the Research Ethics Committee of the Kyoto Institute of Technology (Approval No. 2019-73). For the same study participants, a period of no exercise intervention and a period of exercise intervention were established for 4 weeks each with the exercise intervention period set to come after the non-exercise intervention period (Figure 1). During the exercise intervention period, the exercise program is a day for 6 minutes, was executed a total of 20 times. No specific exercise was performed during the non-exercise intervention period. In addition, in order to verify the changes between the two periods, initial measurements were carried out prior to the beginning of the non-exercise intervention period (hereinafter referred to as 1st-test), after the end of the non-exercise intervention period and before the commencement of the intervention (hereinafter referred to as pre-test), and post-intervention measurements after the end of the exercise intervention period (hereinafter referred to as post-test). This method adopted the work of Umezaki, Nakatani, Yamamoto, Nakasuka, and Hashimoto (2013).The experiment was conducted between December 2019 and February 2020. 


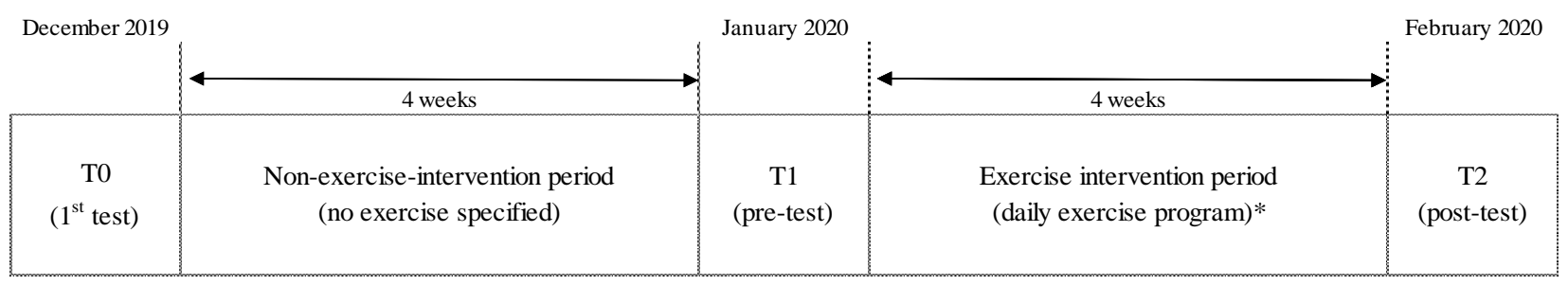

*Subjects did the exercise program for four weeks during the exercise intervention period ( 20 sessions in total)

Figure 1. Measurement protocol

\subsection{Measures}

\subsubsection{The Exercise Program}

The exercise program comprised six different elements: walking, jumping, rotation, support, rhythm, and balance. The "movements to balance the body" of standing, sitting, and turning as well as the "movements to move the body" of walking, running, jumping, and jumping as shown in "diversification of movement" of the early childhood movement guidelines were incorporated. In addition, the content was devised and created so that the seven coordination capabilities of positioning, transformation, rhythm, reaction, balance, connection, and identification could be learned without prejudice (Table 1). The music tempo used in the exercise program was allegretto. Each criteria expanded upon the movements used according to the child's level of learning so that they would not get bored with the challenge of the exercise program, and that their interest in it would be heightened. Regarding methods and the development of movements surrounding each criteria, an explanation including a demonstration was carried out for nursery school workers. Exercise programs were conducted in playrooms or playgrounds where the participants could sufficiently move their bodies in accordance with the rhythm of their lives, weather, events in the playground, etc. The practical content of the exercise program is shown in Figure 2.

Table 1. Exercise program events and coordination classification (Revised based on Azumane [2006], Umezaki et al. [2013], and the Early Childhood Exercise Guidelines [2012])

\begin{tabular}{|c|c|c|c|c|c|c|c|c|c|c|c|}
\hline \multirow{2}{*}{ Event } & \multirow{2}{*}{$\begin{array}{l}\text { Movement } \\
\text { Development }\end{array}$} & \multirow{2}{*}{$\begin{array}{l}\text { Item } \\
\text { (Azumane, } \\
\text { 2006) }\end{array}$} & \multirow{2}{*}{ Method (Azumane, 2006) } & \multicolumn{7}{|c|}{$\begin{array}{l}\text { Coordination Ability } \\
\text { (Azumane, 2006) }\end{array}$} & \multirow{2}{*}{$\begin{array}{c}\text { Early childhood } \\
\text { exercise } \\
\text { guidelines } \\
\text { "Diversification } \\
\text { of movements" }\end{array}$} \\
\hline & & & & 1 & 2 & 3 & 4 & 5 & 6 & 7 & \\
\hline \multirow{4}{*}{ 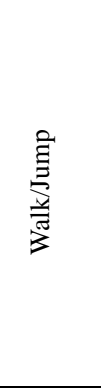 } & 1 & High-knee walk & $\begin{array}{l}\text { Walk with knees raised high while swinging } \\
\text { the arms forward and backward and moving } \\
\text { left, right, front, and back. }\end{array}$ & & & ० & & o & ० & & Walk \\
\hline & 2 & $\begin{array}{l}\text { High-knee } \\
\text { run }\end{array}$ & $\begin{array}{l}\text { Run with knees raised high while swinging } \\
\text { the arms forward and backward and moving } \\
\text { left, right, front, and back. }\end{array}$ & & & ० & & 0 & 0 & & Run \\
\hline & 3 & Skip 1 & $\begin{array}{l}\text { Move back and forth and left and right } \\
\text { while skipping. Skipping is performed } \\
\text { while clapping hands. }\end{array}$ & & ○ & $\circ$ & & $\circ$ & ० & $\circ$ & Hop \\
\hline & 4 & Skip 2 & $\begin{array}{l}\text { Skip while jumping slowly and high. A } \\
\text { backward skip is also performed. }\end{array}$ & & $\circ$ & $\circ$ & $\circ$ & $\circ$ & ○ & $\circ$ & Hop \\
\hline \multirow{2}{*}{$\stackrel{\varrho}{\Xi}$} & 1 & $\begin{array}{l}\text { Double legged } \\
\text { jump } 1\end{array}$ & $\begin{array}{l}\text { Perform two-footed jumps forward, } \\
\text { backward, left, and right. }\end{array}$ & & 0 & 0 & & 0 & ० & & Jump \\
\hline & 2 & $\begin{array}{l}\text { Double legged } \\
\text { jump } 2\end{array}$ & $\begin{array}{l}\text { Perform two-footed jumps forward, } \\
\text { backward, left, and right, with varying } \\
\text { distance. }\end{array}$ & & ○ & $\circ$ & & $\circ$ & $\circ$ & & Jump \\
\hline \multirow{2}{*}{$\stackrel{?}{\Xi}$} & 1 & Ken- pa jump 1 & Perform ken-ken-pa rhythmically. & & $\circ$ & $\circ$ & & $\circ$ & $\circ$ & & Hop \\
\hline & 2 & Ken- pa jump 2 & $\begin{array}{l}\text { Perform ken-ken-pa rhythmically with the } \\
\text { "ken steps" placed on the floor. }\end{array}$ & ○ & ○ & $\circ$ & 0 & 0 & 0 & 0 & Hop \\
\hline \multirow{2}{*}{ 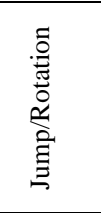 } & 1 & Jump turn 1 & $\begin{array}{l}\text { From a standing position, repeat a } \\
\text { 180-degree turn. }\end{array}$ & & 0 & & & 0 & 0 & & Rotate \\
\hline & 2 & Jump turn 2 & $\begin{array}{l}\text { While moving forward jumping turn } 1 \\
\text { twice. At the third jump, which can be } 180 \\
\text { or } 360 \text { degrees, move to the left or right } \\
\text { continuously. }\end{array}$ & & 0 & ○ & ○ & ○ & ○ & & Rotate \\
\hline 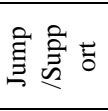 & 1 & Rabbit hop 1 & $\begin{array}{l}\text { Attention is paid to the fingers, palms, head, } \\
\text { and eyes. Land ahead of where the hands } \\
\text { were previously. }\end{array}$ & & & ○ & & $\circ$ & $\circ$ & & Sit/Jump \\
\hline
\end{tabular}




\begin{tabular}{|c|c|c|c|c|c|c|c|c|c|}
\hline & 2 & Rabbit hop 2 & $\begin{array}{l}\text { Attention is paid to the fingers, palms, head, } \\
\text { and eyes. Land ahead of where the hands } \\
\text { were previously. }\end{array}$ & & $\circ$ & ० & ० & ○ & Sit/Jump \\
\hline \multirow{2}{*}{ 言焉 } & 1 & Rhythm run 1 & Run in a "1, 2, 3" rhythm (triple time). & $\circ$ & $\circ$ & & ० & ० & Run/Jump \\
\hline & 2 & Rhythm run 2 & $\begin{array}{l}\text { Perform rhythm run } 1 \text { with varying speed } \\
\text { and rhythm. }\end{array}$ & $\circ$ & ० & ० & $\circ$ & 0 & Run/Jump \\
\hline \multirow{4}{*}{ 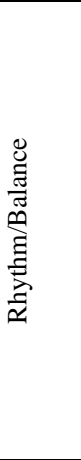 } & 1 & Cross touch 1 & $\begin{array}{l}\text { (1) Raise the left foot inward and touch it } \\
\text { with the right hand. (2) Next, touch the } \\
\text { right foot with the left hand. }\end{array}$ & $\circ$ & ○ & & ० & & Stand/Jump \\
\hline & 2 & Cross touch 2 & $\begin{array}{l}\text { (1) Raise the left foot towards the back } \\
\text { diagonally, and touch it with the right hand. } \\
\text { (2) Touch the right foot with the left hand. }\end{array}$ & $\circ$ & ○ & & ○ & & Stand/Jump \\
\hline & 3 & Cross touch 3 & $\begin{array}{l}\text { (1) Raise the left foot inward and touch it } \\
\text { with the right hand. (2) Next, touch the } \\
\text { right foot with the left hand. (3) Raise the } \\
\text { left foot diagonally toward the back and } \\
\text { touch it with the right hand. (4) Touch the } \\
\text { right foot with the left hand. }\end{array}$ & $\circ$ & ○ & & ० & ○ & Stand/Jump \\
\hline & 4 & Cross touch 4 & Perform Cross touch 3 rhythmically. & $\circ$ & $\circ$ & o & 0 & 0 & Stand/Jump \\
\hline \multirow{3}{*}{ 总 } & 1 & Janken jump 1 & $\begin{array}{l}\text { Jump while moving the limbs in the form of } \\
\text { "rock" and "paper." The arms are by the side } \\
\text { of the body during "rock" and up during } \\
\text { "paper." }\end{array}$ & $\circ$ & ○ & & & ० & Jump \\
\hline & 2 & Janken jump 2 & $\begin{array}{l}\text { Jump while moving the limbs in the form of } \\
\text { "rock," "scissors," and "paper." The arms } \\
\text { are by the side of the body during "rock," up } \\
\text { during "paper," and front and back during } \\
\text { "scissors," with legs and arms coordinated. }\end{array}$ & $\circ$ & ○ & & & ० & Jump \\
\hline & 3 & Janken jump 3 & $\begin{array}{l}\text { Perform the movement of } 1 \text { and } 2 \text { with } \\
\text { varying speed, mixing up "rock" "paper" } \\
\text { and "scissors" between the arms and legs. }\end{array}$ & $\circ$ & ○ & $\circ$ & ० & ० & Jump \\
\hline
\end{tabular}

Coordination Ability $1:$ Positioning , 2: Transformation , 3:Rhythm , 4: Reaction , $5:$ Balance , $6:$ Connection , $7:$ Identification

*The circles show emphasis in the item.

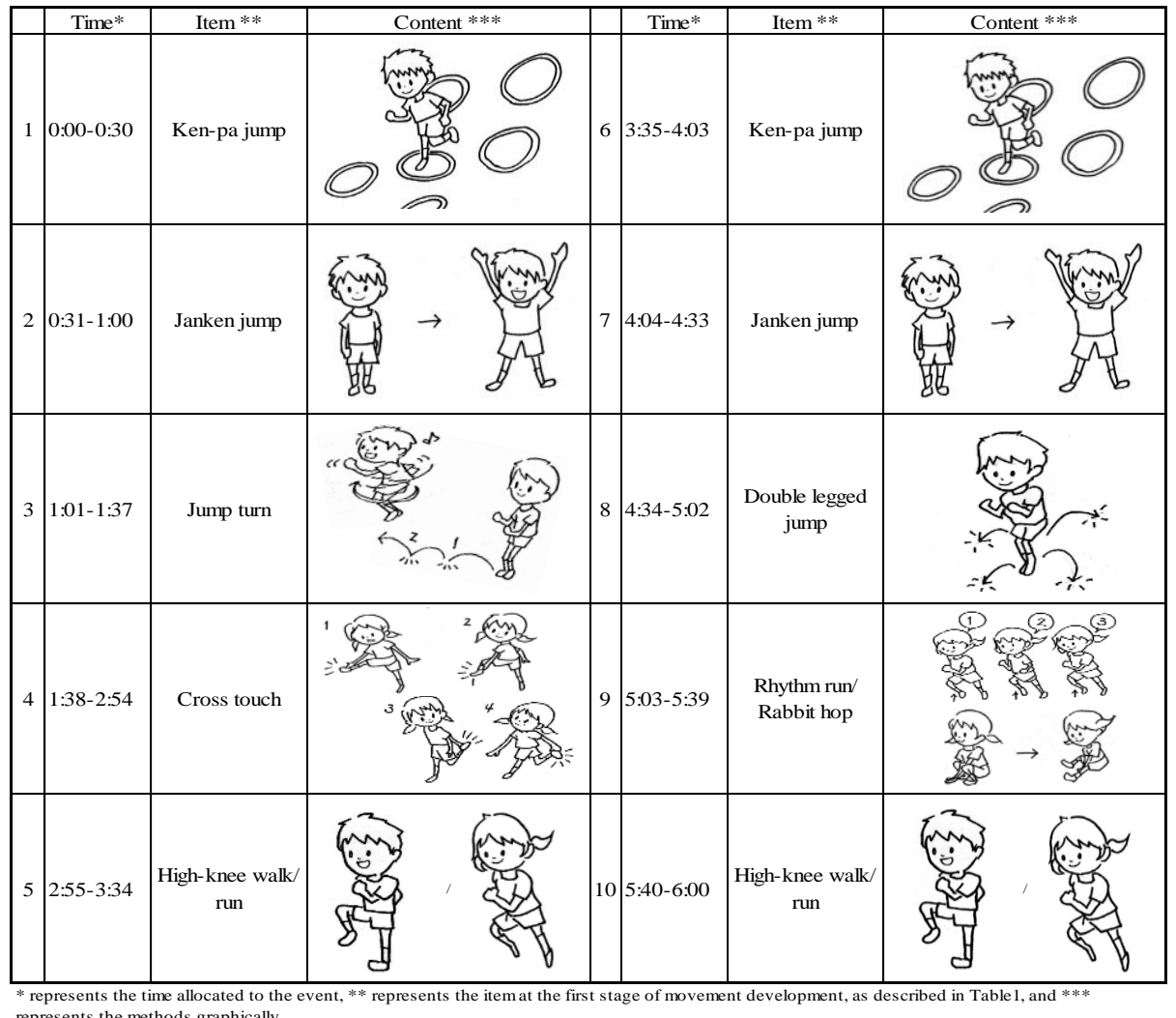

Figure 2. Coordination exercise centered on rhythmic play 


\subsubsection{Observational Assessment}

The movements of the study participants were photographed from the side using a digital video camera (SONY Co., HDR-CX470), and the captured images were observed and evaluated. The evaluation criteria were created with reference to Matsumoto (1992), who clarified the validity of the structure and function of dance, and Gough (1997), who clarified the aims of movement to enrich expression into four elements, which were added to and revised based on the evaluation criteria of Yoshimi (2020a, 2020b). There were 12 criteria established for the evaluation of observations of the potential for physical expression, 3 criteria relating to motion, 2 criteria relating to space, 2 criteria relating to dynamics, 2 criteria relating to time, 3 criteria relating to relationships, with scoring for these evaluation criteria based on a 5-point scale of "Applicable (5 points)," "Somewhat applicable (4 points)," "neither (3 points)," "not very applicable (2 points)," and "not applicable (1 point)" (Table 2). Two observers with experience in instructing young children in dance conducted the observational evaluation. The mean scores for each evaluation were tested for agreement between the two evaluators.

Table 2. Observational items of physical-expression ability

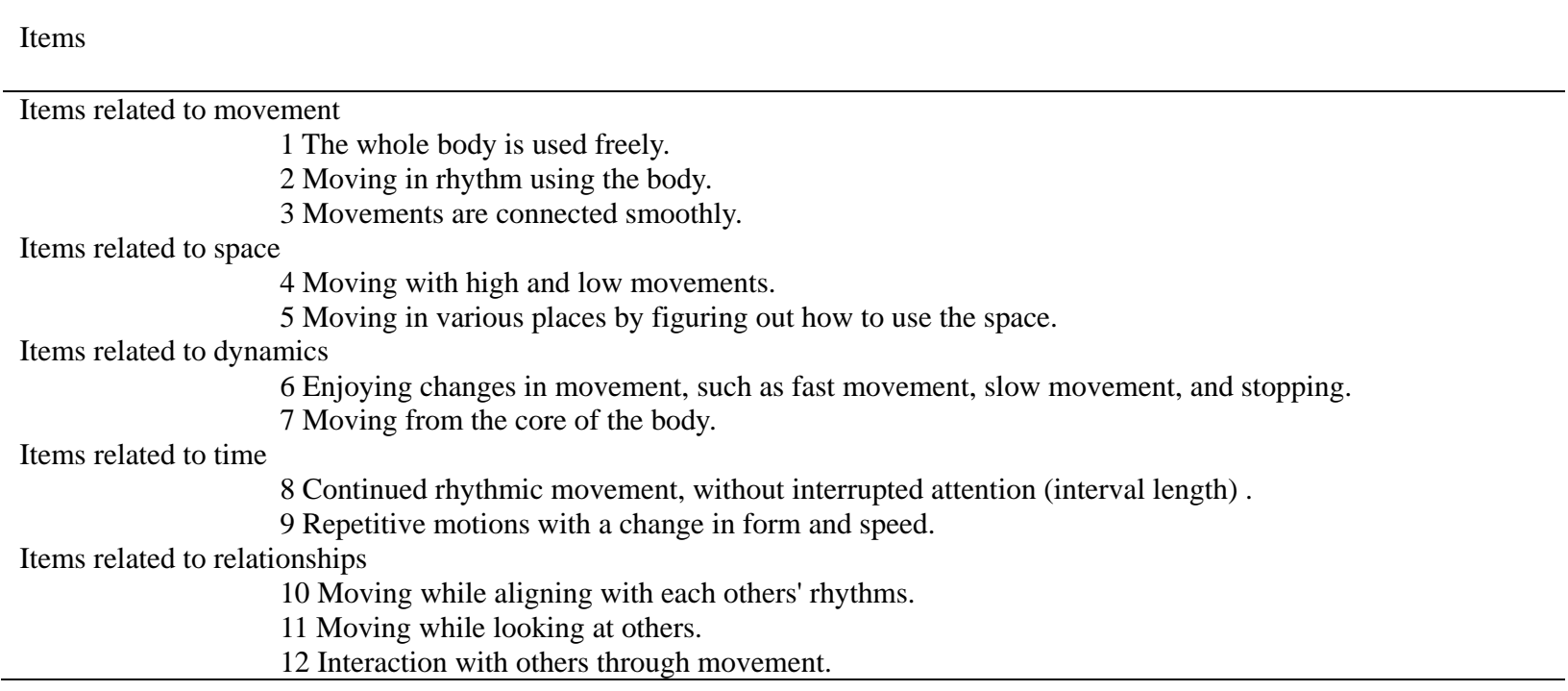

\subsection{Data Analysis}

An unmatched t-test was used to test the mean difference of the two evaluation scores regarding the observational evaluation of the potential for physical expression ability. If no significant differences were found, Spearman correlation coefficients were leveraged to investigate the degree of agreement among the evaluation trends between evaluators. To investigate the changes in the three measurement values (1st-test, pre-test, and post-test) for each measurement criteria, a two-factor analysis of variance was performed through repeated measurements to examine the presence or absence of interactions between the period in which the measurements were taken and the school grade of the students. When a main effect was confirmed during the periods in which measurements were taken, multiple comparative tests using the Bonferroni method were employed. These statistical analyses used the statistical software IBM SPSS Statistics 25 . The significance level was $5 \%$.

\section{Results}

Morphological changes per month, calculated from height and weight measurements performed twice (January and February) at kindergartens, came to height $+0.28 \mathrm{~cm}$ and weight $+0.07 \mathrm{~kg}$ for 3-year-olds, height $+0.31 \mathrm{~cm}$ and weight $+0.1 \mathrm{~kg}$ for 4 -year-olds, and height $+1.1 \mathrm{~cm}$ and weight $+0.21 \mathrm{~kg}$ for 5 -year-old children. Morphological changes in height and weight per month were similar in both boys and girls compared with the same aged children in the Infant and Child Physical Development Survey (Ministry of Health, Labor and Welfare [MHLW], 2010). Thus, the study participants are considered a population with average morphological characteristics. There was no significant difference between the mean of the two evaluators according to the observed evaluation score of the potential for physical expression. Correlation coefficients for the Motion Enrichment Observation Rating scores among evaluators were 0.823 for the motion criteria, 0.827 for the space criteria, 0.874 for the dynamic criteria, 0.856 for the time criteria, and 0.863 for the relationship criteria. All of these coefficients show a score of $\mathrm{p}<.05$, a significant positive correlation.

\subsection{The Effect of the Potential for Physical Expression}

The two-factor analysis of variance, based on the measurement period and grade, showed an interaction between 
criterion $11(\mathrm{~F}=453.62)$ regarding relationships and criterion $12(\mathrm{~F}=548.53)$ also regarding relationships. Therefore, the simple main effects of the factors were examined (Table 3). Multiple comparative tests showed significant differences between all measures among 3 year old children in relation to criteria 11 and 12, both related to relationships, with high values shown in the order of post-test, pre-test, and 1st-test. Significant differences were observed between the 1st-test and post-test for 4-year-old and 5-year-old children, and significant main effects were observed in the period of measurement $(\mathrm{F}=400.69)$ and school grade $(\mathrm{F}=3.36)$ with criterion 10 related to relationships showing the highest values in the order of post-test, pre-test, and 1st-test, from highest to lowest. Multiple comparisons revealed significant differences among all grade measures, with high values in the order of post-test, pre-test, and 1st-test, from highest to lowest. Significant major effects were only observed at the period of observation in the 3 criteria related to movement, 2 criteria related to space, 2 criteria related to dynamics, and 2 criteria related to time. Multiple comparative tests showed significant differences between the 1st-test and post-test and between the pre-test and post-test.

Table 3. Results of two-factor analyses of variance for the measures

\begin{tabular}{|c|c|c|c|c|c|c|c|c|}
\hline \multirow{2}{*}{ Items (unit) } & \multirow{2}{*}{ Age } & \multirow[t]{2}{*}{$1 \mathrm{st}$} & \multirow{2}{*}{$\frac{\text { Pre }}{\text { Mean } \pm \text { SD }}$} & \multirow[t]{2}{*}{ Post } & \multicolumn{2}{|c|}{$\begin{array}{l}\text { Main effect } \\
\mathrm{F}(\mathrm{p}) *\end{array}$} & \multirow{2}{*}{$\begin{array}{c}\text { Interaction } \\
\mathrm{F}(\mathrm{p}) * \\
\text { Measurement } \\
\text { time } \times \text { Age }\end{array}$} & \multirow{2}{*}{ Effect of factors } \\
\hline & & & & & Measurement time & Age & & \\
\hline \multirow{3}{*}{$\begin{array}{l}\text { Motion1 } \\
\text { (point) }\end{array}$} & 3 & $3.84 \pm 0.64$ & $3.79 \pm 0.53$ & $4.93 \pm 0.22$ & & & & \\
\hline & 4 & $3.85 \pm 0.51$ & $3.84 \pm 0.50$ & $4.86 \pm 0.62$ & $195.13(0.00)^{*}$ & $0.07(0.93)$ & $0.18(0.95)$ & 1 st, pre $<$ post \\
\hline & 5 & $3.80 \pm 0.70$ & $3.82 \pm 0.56$ & $4.85 \pm 0.32$ & & & & \\
\hline \multirow{3}{*}{$\begin{array}{r}\text { Motion2 } \\
\text { (point) }\end{array}$} & 3 & $3.60 \pm 0.72$ & $3.59 \pm 0.60$ & $4.71 \pm 0.37$ & & & & \\
\hline & 4 & $3.80 \pm 0.47$ & $3.70 \pm 0.56$ & $4.74 \pm 0.63$ & $179.04(0.00)^{*}$ & $0.71(0.49)$ & $0.38(0.82)$ & $1 \mathrm{st}$, pre $<$ post \\
\hline & 5 & $3.73 \pm 0.63$ & $3.64 \pm 0.62$ & $4.80 \pm 0.33$ & & & & \\
\hline \multirow{3}{*}{$\begin{array}{l}\text { Motion3 } \\
\text { (point) }\end{array}$} & 3 & $3.33 \pm 0.76$ & $3.45 \pm 0.62$ & $4.64 \pm 0.52$ & & & & \\
\hline & 4 & $3.58 \pm 0.54$ & $3.51 \pm 0.58$ & $4.80 \pm 0.65$ & $191.17(0.00)^{*}$ & $1.89(0.16)$ & $0.78(0.54)$ & 1 st, pre $<$ post \\
\hline & 5 & $3.70 \pm 0.70$ & $3.48 \pm 0.64$ & $4.82 \pm 0.33$ & & & & \\
\hline \multirow{3}{*}{$\begin{array}{l}\text { Space4 } \\
\text { (point) }\end{array}$} & 3 & $3.45 \pm 0.78$ & $3.50 \pm 0.64$ & $4.79 \pm 0.31$ & & & & \\
\hline & 4 & $3.60 \pm 0.65$ & $3.64 \pm 0.59$ & $4.81 \pm 0.63$ & $181.57(0.00)^{*}$ & $0.75(0.47)$ & $0.64(0.64)$ & 1 st, pre $<$ post \\
\hline & 5 & $3.73 \pm 0.75$ & $3.62 \pm 0.63$ & $4.79 \pm 0.35$ & & & & \\
\hline \multirow{3}{*}{$\begin{array}{l}\text { Space5 } \\
\text { (point) }\end{array}$} & 3 & $3.22 \pm 0.82$ & $3.31 \pm 0.60$ & $4.66 \pm 0.45$ & & & & \\
\hline & 4 & $3.44 \pm 0.68$ & $3.55 \pm 0.65$ & $4.77 \pm 0.64$ & $200.64(0.00)^{*}$ & $2.13(0.13)$ & $0.49(0.75)$ & 1 st, pre $<$ post \\
\hline & 5 & $3.56 \pm 0.68$ & $3.47 \pm 0.60$ & $4.79 \pm 0.38$ & & & & \\
\hline \multirow{3}{*}{ Dynamics6 (point) } & 3 & $3.24 \pm 0.82$ & $3.40 \pm 0.63$ & $4.88 \pm 0.26$ & & & & \\
\hline & 4 & $3.63 \pm 0.68$ & $3.66 \pm 0.56$ & $4.83 \pm 0.63$ & $228.22(0.00)^{*}$ & $2.78(0.06)$ & $1.67(0.16)$ & 1 st, pre < post \\
\hline & 5 & $3.62 \pm 0.67$ & $3.67 \pm 0.61$ & $4.92 \pm 0.22$ & & & & \\
\hline \multirow{3}{*}{ Dynamics7 (point) } & 3 & $3.17 \pm 0.80$ & $3.34 \pm 0.61$ & $4.88 \pm 0.32$ & & & & \\
\hline & 4 & $3.44 \pm 0.76$ & $3.60 \pm 0.62$ & $4.84 \pm 0.63$ & $242.20(0.00)^{*}$ & $1.54(0.22)$ & $0.93(0.45)$ & 1 st, pre $<$ post \\
\hline & 5 & $3.44 \pm 0.70$ & $3.55 \pm 0.60$ & $4.91 \pm 0.23$ & & & & \\
\hline \multirow{3}{*}{$\begin{array}{l}\text { Time8 } \\
\text { (point) }\end{array}$} & 3 & $3.59 \pm 0.86$ & $3.57 \pm 0.73$ & $4.71 \pm 0.56$ & & & & \\
\hline & 4 & $3.76 \pm 0.68$ & $3.74 \pm 0.54$ & $4.82 \pm 0.63$ & $155.21(0.00)^{*}$ & $1.15(0.32)$ & $0.82(0.51)$ & 1 st, pre $<$ post \\
\hline & 5 & $3.47 \pm 0.72$ & $3.67 \pm 0.61$ & $4.82 \pm 0.35$ & & & & \\
\hline \multirow{3}{*}{$\begin{array}{l}\text { Time9 } \\
\text { (point) }\end{array}$} & 3 & $2.91 \pm 0.88$ & $2.83 \pm 0.66$ & $4.60 \pm 0.51$ & & & & \\
\hline & 4 & $2.84 \pm 0.77$ & $2.80 \pm 0.73$ & $4.78 \pm 0.64$ & $420.69(0.00)^{*}$ & $0.56(0.57)$ & $0.75(0.56)$ & 1 st, pre $<$ post \\
\hline & 5 & $2.64 \pm 0.79$ & $2.77 \pm 0.57$ & $4.71 \pm 0.55$ & & & & \\
\hline \multirow{3}{*}{$\begin{array}{l}\text { Relationships } 10 \\
\text { (point) }\end{array}$} & 3 & $2.55 \pm 0.77$ & $3.10 \pm 0.63$ & $4.64 \pm 0.61$ & & & & 1 st $<$ pre $<$ post \\
\hline & 4 & $2.91 \pm 0.76$ & $3.20 \pm 0.51$ & $4.83 \pm 0.63$ & $400.69(0.00)^{*}$ & $3.36(0.04) *$ & $1.18(0.32)$ & \\
\hline & 5 & $2.92 \pm 0.49$ & $3.11 \pm 0.48$ & $4.94 \pm 0.21$ & & & & $3<4,5$ \\
\hline \multirow{3}{*}{$\begin{array}{l}\text { Relationships } 11 \\
\text { (point) }\end{array}$} & 3 & $2.48 \pm 0.67$ & $2.84 \pm 0.46$ & $4.16 \pm 0.73$ & & & & $\begin{array}{l}3: 1 \text { st }<\text { pre }<\text { post } \\
4: 1 \text { st }, \text { pre }<\text { post }\end{array}$ \\
\hline & 4 & $2.66 \pm 0.69$ & $2.89 \pm 0.34$ & $4.69 \pm 0.70$ & $453.62(0.00)^{*}$ & $7.52(0.00)^{*}$ & $3.82(0.01)^{*}$ & $\begin{array}{l}5: 1 \text { st }, \text { pre }<\text { post } \\
1 \text { st }: 3<5\end{array}$ \\
\hline & 5 & $2.83 \pm 0.43$ & $2.89 \pm 0.39$ & $4.86 \pm 0.40$ & & & & $\begin{array}{l}\text { pre : n.s. } \\
\text { post : } 3<4<5\end{array}$ \\
\hline \multirow{3}{*}{$\begin{array}{l}\text { Relationships } 12 \\
\text { (point) }\end{array}$} & 3 & $2.48 \pm 0.67$ & $2.79 \pm 0.43$ & $3.76 \pm 0.70$ & & & & $\begin{array}{l}3: 1 \text { st }<\text { pre }<\text { post } \\
4: 1 \text { st }, \text { pre }<\text { post }\end{array}$ \\
\hline & 4 & $2.61 \pm 0.63$ & $2.88 \pm 0.34$ & $4.40 \pm 0.80$ & $548.53(0.00)^{*}$ & $28.81(0.00)^{*}$ & $7.38(0.00)^{*}$ & $\begin{array}{l}5: 1 \text { st }, \text { pre }<\text { post } \\
1 \text { st }: 3<5\end{array}$ \\
\hline & 5 & $2.83 \pm 0.43$ & $2.89 \pm 0.37$ & $4.74 \pm 0.44$ & & & & $\begin{array}{l}\text { pre : n.s. } \\
\text { post : } 3<4<5\end{array}$ \\
\hline
\end{tabular}

\section{Discussion}

In this study, the effects of an exercise program centered on rhythm play on the sociability of the young child were examined, focusing on the potential for physical expression from the viewpoint of a sociability that is based on a 
relationship with others. Since the main effects of each grade were not recognized in the criteria related to motion, space, dynamics, and time, the exercise program prepared in this study seemed to have been proactively engaged in regardless of the grade. In addition, since no interaction has been observed for the criteria related to motion, space, dynamics, and time, it was suggested that aging does not bring about a richness of movement, but that experience brings about the sociability of a richness of motion. Similar to the results of this study, Koichi (2013) found that the richness of physical expression in infants and young children as considered by childcare workers showed a similar pattern among 3-year-old children, 4-year-old children, and 5-year-old children. In addition, Furuichi (2013) showed that a characteristic of the physical expressions of 3-year-old child, 4-year-old and 5-year-old children is that they are group expressions and this is shown to be a factor of rich physical expression that is not apparent in 1-year-old and 2-year-old children. From these results, it was confirmed that experiencing an exercise program in a group is a day-care activity that leads to rich physical expressions for children aged 3,4 , and 5 years.

As a characteristic surrounding grades, the lowest score was found in the 1st-test of criterion 2 regarding movement in 3 -year-old children, but the post-test did not show a large difference in the scores for 4-year-old children. In addition, the 1st-test of criterion 9 regarding time showed a higher score than that of 4- and 5-year-old children, displaying a characteristic of 3-year-old children. Moreover, it was recognized that movements were repeated through closely observing the change of movement method and speed. That is to say, it was shown that 3-year-old children observed and imitated the motion, before repeating it, in comparison with 4- and 5-year-old children.

Among 4-year-old children, the $1^{\text {st }}$-test score of criteria 1 and 2 regarding movement were higher than that of 3-year-old and 5-year-old children, and the score of criterion 8 regarding time is also higher than that of 3-year-old and 5-year-old children. From this, it was shown as a characteristic of 4-year-old children that the whole body moved in tandem with the rhythm, and that as per criterion 8 regarding time, 4-year-olds continued to move in tandem with the rhythm without wavering.

In addition, it became clear that a similar tendency was shown when the score transition of 3-year-old and 4-year-old children was observed. Criteria 1 and 2 regarding movement and the 2 regarding time showed high values in the descending order of post-test, 1st-test, and pre-test. Criteria related to space, dynamics, and relationships were found in the descending order of post-test, pre-test, and 1st-test. In other words, it became clear that outside of the three movement criteria, it was common for 3-year-old and 4-year-old children to share characteristics. It is noteworthy that criterion 9 regarding time for 3-year-old children, criteria 1 and 2 regarding movement, and criterion 8 regarding time for 4-year-old children were higher than for the other grades. All the scores were increased by the exercise program; however, unique characteristics that emerged in the data were that for 3-year-olds, it was shown that it brought about a change in their movement that repeated itself; for 4-year-old children, they continued moving in tandem with the rhythm without interruption, they used their whole body, and they match the rhythm.

For 5-year-old children, scores tended to increase for criterion 1 regarding movement and 2 regarding time. In the 1 st-test of criterion 1, regarding movement, scores were lower than those of 3-year-old and 4-year-old children. One characteristic of this group was that the stretching of 5-year-old children was shown to be significantly affected by the experience of the exercise program in comparison to that of 3-year-old and 4-year-old children. Similarly, in terms of the time-related criteria 8 and 9, 1st-test scores were the lowest when compared with children aged 3 and 4 , and in the post-test the gap in scores between children aged 3 and 4 was small. Therefore, in 5-year-old children, these can be thought to be heightened by continuing to engage in the exercise program, moving in tandem with the rhythm without interrupting their mood, observing the changes in the shape and speed of the movement, and continuously moving while imitating it. In the Kindergarten Education Guidelines, Chapter 1, General Rules, Section 2 Kindergarten Education, regarding the qualities, abilities, and "form we wish to cultivate by the end of childhood," it states: "(10) Rich Sensibilities and Expressions - While leveraging their sense of touch through events that stir the heart, they will express their feelings and thoughts by themselves, experience the joy of expressing them with their friends, taste the joy of expression, and become motivated to express themselves." This indicates that the pleasant experience of expressing what one wishes by oneself and the sharing of this process with others is regarded as important in Kindergarten education. As the transition score of the criteria regarding time showed, for the 5-year-old children who are part of the last school year studied, in the process of engaging in the exercise program with friends, behaviors that changed movements were observed as a mechanic of expressions, illuminating the characteristics of 5-year-old children.

One aspect common across all grades was that it became clear that the two criteria regarding dynamics increased by increasing the number of repetitions. Moreover, in the post-test, 3-year-old children showed a higher score than 4-year-old children, and it was shown that the experience of the exercise program from the age of 3 could lead to a richness of motion when dynamic movements change and movement from the center of the body becomes possible. The Kindergarten Education Guidelines, Chapter 1, General Rules, Section 3 Dealing with Content, states: "(3) Based on life experience and development, they can enjoy various experiences by themselves, and so that they can be allowed to 
obtain sufficient motivation to express themselves, different play sets and equipment will be prepared; they will gain different materials and manners of expression; they will become able to consider the expressions of others and they will come to value the process of expression so that they may enjoy it" (Ministry of Education, Culture, Sports, Science and Technology, 2017). This shows the importance of considering the creation of an environment that can adequately draw out abilities that young children hold based on their level of development and increasing motivation for activities that enable young children to freely express themselves as they wish. Considering changes in the scores of the two dynamic criteria, it is thought that even in the young stage of 3-year-old children, the richness of movement is promoted through rhythmic play, which enables them to freely express themselves and spurs their motivation to express themselves based on their individual development.

Regarding relationship criteria, a separate study by the author (Yoshimi et al., 2021) has shown that the experience of movement-based exercise programs in groups reduces differences in age. The 2018 Explanation of the Kindergarten Educational Guidelines details the characteristics of young children in regards to others and states that "during early childhood, a person's life moves from being centered on developing the ego and expressing oneself, to a life in which they interact with others, develop an awareness of the existence of others with a feeling of having to restrain oneself and the foundation for the development of oneself constructed" (Ministry of Education, Culture, Sports, Science and Technology, 2018). It is suggested that even if emotion and feelings are not spoken as words as part of the process of growth, the scope of consciousness expands from the self to others, leading to the development of a mind that is conscious of others through the sprouting of the ego. In the 1st-test of criteria 10,11, and 12 that relate to relationships, the spread of one's consciousness in line with aging is shown. It was also shown that the three criteria related to relationships tended to increase more by raising the number of repetitions.

Considering the three criteria related to relationships individually, regarding criterion 10, in the 1st-test of 3-year-old children, the gap between them and 4 and 5-year-old children was large, but in the pre-test, the difference between 3 -year-olds and 5-year-olds children shrank. Therefore, it became clear that they were conscious of involvement with others without the intervention of a continuous exercise program. For 4-year-old children, it became clear that there is no difference with 5-year-old children, and in the pre-test, they showed the highest score. It was shown that even if you do not participate in the exercise program regularly, if you increase the repetitions, scores could also increase. With 5-year-old children, since no gap was confirmed with the 4-year-old children in the pre-test, it was shown that the gap with 4-year-old children contracted based on experience. With criterion 10 regarding relationships, it became clear that across all grades, values increased with the second attempt. Particularly, it became clear that the score of 4-year-old children exceeded that of the score of 5-year-old children by experiencing the exercise program twice, and that they were greatly affected to move while feeling the rhythm in tandem with others. Regarding items 11 and 12, which are related to relationships, there were no differences in pre-test scores across grades, but a difference in ages was shown because 3-year-old children were greatly influenced by experiencing the exercise program once, but 4- and 5-year-old children were influenced by experiencing it on a continuous basis. In the post-test, differences across grades were shown, suggesting that they increased with age. These results suggest that, regarding criteria related to relationships, participation in the exercise program from the age of 3 may promote the development of sociability thereafter. Furthermore, it is thought that children in early childhood have begun to engage with other children from around three years of age, moving from playing by themselves to playing in groups, and beginning to want to communicate with each other. Parten (1932) suggested that the stage prior to actual action is "playing alone" or being a "bystander." It was observed that young children, who in the $1^{\text {st }}$ test were absorbed in mimicking the movements of others, such as moving in line with changes in the movements of exercise programs or in tandem with music, in the post-test looked at friends' faces while moving, sang along, or moved in sync with one another. Like the exercise program in this study, in an environment where the child is moving their body with childcare practitioners and other children, the desire to connect with someone through movement was drawn out as a movement, suggesting that movement leads to the development of a sociability, such as with the three criteria related to relationships of "moving while matching the rhythm of each other," "moving while looking around you," and "interacting through movement." Criteria related to relationships are linked to communication with other children through movement, such as engaging with them while enjoying the movement of exercise programs, and interaction through movement Many young children were aware of mimicking their movements in the 1st-test and pre-test, but in the post-test, at the same time as imitating their movements and looking at nearby friends, it was observed that their expressions changed, that they moved in tandem with each other's rhythms, and that they touched shoulders and interacted with each other while moving to the exercise program. This is similar to the fact that in the $1^{\text {st }}$ test and pre-test shown in Parten (1932), children enjoyed the same rhythmic play in the same space, such as in "parallel play," but in the post-test they engaged with other children while enjoying movements by communicating through collective movements such as "joint play" and "cooperative play," and they were observed to actively interact through movements. From these facts, it became clear that criterion 10 regarding relationships was greatly influenced by the act of engaging with the exercise program even once in all grades. Scores for criteria 11 and 12, regarding 
relationships, were higher for 4-year-old and 5-year-old children after continuous experience of the exercise program; it also became clear that the change in the score was great in the case of 3-year-old children after engaging in the program just once and that it influenced sociability. Therefore, it became clear that the experience of the exercise program early in one's life affects the potential for physical expression in young children, that it is linked to the development of sociability through movement, and that the movement of the young child brings about richer physical expressions.

From these above facts, it was shown that the practice of the exercise program influenced the richness of the movement in all the grades: 3-year-old, 4-year-old, and 5-year-old children. It was clarified that through an exercise program that included rhythm play, even if not continuously but simply experiencing the program a number of times, the richness of the children's movements increased, while at the same their consciousness turned from themselves to others, and a behavior was drawn out of them in which they actively attempted to communicate. Particularly regarding relationships, the efforts made by children aged 3 greatly impact sociability through movement, confirming that each individual experience is valuable for young children and gives rise to rich physical expressions. It became clear that the potential for physical expression plays a major role in interaction through movement, creating a dynamic connection with others in the space and time in which the play is carried out, by increasing the sense of rhythm, and creating a relationship that connects movements. In other words, relationships can be considered the key to creating new forms of expression that enrich movements and link them to other movements, children, and leaders.

\section{Conclusion}

In this study, the effect an exercise program centered on rhythm play on the sociability of young children was examined, with a focus on the potential for physical expression (richness of the movement) from the viewpoint of social development based on relationships with other people. Examining the features of the physical expression of 3-year-old, 4-year-old, and 5-year-old children, we confirmed that the experience of the exercise program in groups led to rich physical expressions for all three groups of children.

1) For 3-year-old children, in the 1st-test of criterion 9, related to time, their score was higher than that of 4-year-old and 5-year-old children, and one observed feature was that they repeatedly moved by closely observing the change in the shape and speed of the movement. For 5-year-old children, the score of criterion 1 regarding movement before the exercise program and criterion 9 regarding time were the lowest, and it became clear that continuing to move in tandem with the rhythm without wavering improved the shape of movements, the speed, and changes while engaging in the exercise program by continuing to move while imitating, a difference between them and 3-year-old and 4-year-old children.

2) For 4-year-old children, it was shown that the key characteristic criteria were that they continued moving in tandem with the rhythm without wavering, criterion 8 regarding time, and also criteria 1 and 2 regarding movement; that the whole body was used to stretch, and that they moved in accordance with the rhythm. Compared with 3-year-old and 5-year-old children, the effect of the potential of physical expressiveness is greater in 4-year-old children, indicating that engaging in the exercise program from around 4 years of age is desirable and effective.

In criterion 10, regarding relationships, it became clear that the potential for physical expression increased even if one did not participate in the program consistently but instead just a number of times, that this effect was especially large on 3 -year-old children, and that this is the timeframe in which experiencing it even once affects the development of sociability. Regarding criteria 11 and 12 concerning relationships, it became clear that engaging in the exercise program increased these scores in tandem for all grades. In the post-test, differences in grades were revealed, and it is suggested that, although there were differences in development according to age, the potential for physical expression increased with age, leading to increased sociability.

3) It became clear that the experience of the exercise program did not bring about a richness of movement through aging, but that the experience of movement centered on rhythm play promotes a richness of movement, and this improves sociability. Especially, it became clear that engagement from the age of around 4 years, which is characterized by repeating the movement in time with the rhythm, leads to communication through movement, and that the enhancement of the potential for physical expression in the relationship promotes the development of the sociality.

Although it was necessary to establish a control group, considering the burden on the childcare practitioners and time-constraints arising from annual events, a non-exercise intervention period and exercise intervention period were set for the same subjects, and the effect of the exercise program was verified by a comparison of each measurement value. In the future, it should be possible to obtain information that was not clarified in this study by setting up and examining control groups in other kindergartens and investigating a large group of research subjects. 


\section{References}

Azumane, A. (2006). 65 coordination exercises that change physical education classes: Integrated and scientific teaching methods for the mind and body. Tokyo: Meijitosho Shuppan Corporation.

Early Childhood Exercise Guidelines. (2012). Guidelines for early childhood physical activity (pp. 123-132). Tokyo: Nihon Education Books.

Evridiki, Z., Aggeliki, T., \& Vassiliki, D. (2004). The effects of a developmentally appropriate music and movement program on motor performance. Early Childhood Research Quarterly, 19, 631-642. https://doi.org/10.1016/j.ecresq.2004.10.005

Furuichi, H. (1996). A consideration of many sides in body expression activities in children. Educare, 16, 19-25.

Furuichi, H. (2013). Hoiku Hyogen Gijutsu: yutaka ni Sodatsu/Sodateru Karada Hyogen (Childcare expression technology: Physical expression to grow and nurture abundantly) (pp. 11-13). Tokyo: Minerva Shobo.

Gough, M. (1997). In touch with dance (Translated by M. Tamagawa, pp. 19-31). Tokyo: Tamagawa University Press.

Kameyama, Y. (2008). Research concerning the introduction of dance and movement of expression into early-childhood education: In the context of rhythmic dance. Bulletin of Nippon Sports Science University, 37, 97-106.

Matsumoto, C. (1992). Dance education 1. Principles of dance education. Tokyo: Tokuma Shoten Publishing Co. Ltd.

Ministry of Education, Culture, Sports, Science and Technology. (2017). Kindergarten education guidelines (pp. 4-5). Retrieved from https://www.mext.go.jp/content/1384661_3_2.pdf

Ministry of Education, Culture, Sports, Science and Technology. (2018). Yochien Kyoiku Yoryo (Kindergarten Education Guidelines; pp. 11). Retrieved from https://www.mext.go.jp/content/1384661_3_3.pdf

Ministry of Health, Labor and Welfare. (2010). National growth survey on preschool children. Retrieved from https://www.mhlw.go.jp/stf/houdou/0000042861.html

Ministry of Health, Labor and Welfare. (2017). Yochien Kyoiku Yoryo Kaisetsu (Explanation of the nursery school childcare guidelines; pp. 33-34). Retrieved from https://www.mhlw.go.jp/file/06-Seisakujouhou-11900000-Koyoukintoujidoukateikyoku/0000160000.pdf

Nakayama, T., \& Nakai, A. (2012). Effects of the soccer school in consideration of the characteristics of the growth and development of preschool children and the acquisition of sociality on mental state and physical strength in preschool children. Kinki University of Health and Welfare, 13(1), 23-29.

Nasukawa, T., \& Ikeda, Y. (1995). Yochi no Karada Hyogen no 'Imi' ni tsuite no Kenkyu (II) - 'Nawatobi' Undo ga Kataru Naimen Sekia-i (Research on "Meaning" of Body Representation of Young Children (II)-Inner World Speaking by "Nagaki" Movement-). Heart Hyokyo Institutional Repository, 15(1), 87-96.

Parten, M. B. (1932). Social participation among preschool children. Journal of Abnormal and Social Psychology, 27, 243-269. https://doi.org/10.1037/h0074524

Sugimura, S., Asakawa, A., Okahana, K., Zaimitsu, Y., Matsumoto, S., Hayashi, Y., ... Ochiai, S. (2010). The role of movement in young children's development. The Annals of Education Research, 38, 295-300.

Takenawa, M., Takeda, T., Kikuchi, H., \& Nakagawa, K. (2008). Teaching program for kids in aerobics. Bulletin of the Continuing Education Research Institute. Hokkaido Asai Gakuen University, 11, 213-227.

Tomita, H., Otobuchi, R., \& Matsushima, A. (2014). The effect of an exercise program that includes rhythmic motion on the sense of rhythm and physical fitness of young children. Bulletin of the Shizuoka Institute of Science and Technology, 22, 51-56.

Umezaki, S., Nakatani, T., Yamamoto, D., Nakasuka, T., \& Hashimoto, M. (2013). Effects of coordination exercise on the motion capacity of preschool children: Quantitative and qualitative changes in throwing and catching ability. Japan Journal of Human Growth and Developmental Research, 59, 27-40. https://doi.org/10.5332/hatsuhatsu.2013.27

Wakamatsu, M. (1989). Development of the physical-expression ability of 4-year-old children. Shiraume Gakuen Junior College Bulletin, 25, 45-56.

Wakamatsu, M. (1990). Development of the physical-expressive ability of 5-year-old children. Shiraume Gakuen Junior College Bulletin, 26, 69-80. 
Wakamatsu, M. (1993). Development of the physical-expression ability of 3-year-old children. Shiraume Gakuen Junior College Bulletin, 29, 49-61.

Yoshimi, E. (2020a). Study on the cooperative movement of infants: Focus on the richness of movement seen in rhythmic movements (2). Annual Reports of Studies, Tokiwakai Junior College, 48, 87-102.

Yoshimi, E. (2020b). Study on the cooperative movement of infants: Focus on the richness of movement seen in rhythmic movements (3). Tokiwakai Junior College Early-Childhood Education Journal, 36, 30-43.

Yoshimi, E., \& Katayama, H. (2019). Study on the cooperative movement of infants: Focus on the richness of movement seen in rhythmic movements (1). Tokiwakai Junior College Early-Childhood Education Journal, 35, 58-71.

Yoshimi, E., Nomura, T., \& Kida, N. (2021). A study of young children's coordinated movement: The effects of a rhythmic-play exercise program on physical-expression ability. Advances in Physical Education, 11(1). https://doi.org/10.4236/ape.2021.111009

\section{Copyrights}

Copyright for this article is retained by the author(s), with first publication rights granted to the journal.

This is an open-access article distributed under the terms and conditions of the Creative Commons Attribution license which permits unrestricted use, distribution, and reproduction in any medium, provided the original work is properly cited. 